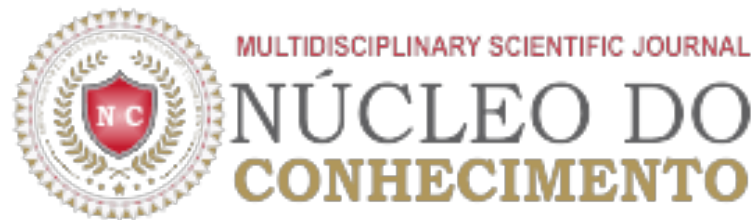

\section{A Relevância da Meritocracia como Fator de Governança Pública no Instituto Federal de Educação do Mato Grosso}

\section{ARTIGO ORIGINAL}

NACIFE, Jean Marc $\stackrel{[1]}{ }$, COLOSSI, Nelson $\stackrel{[2]}{[2}$

NACIFE, Jean Marc; COLOSSI, Nelson. A Relevância da Meritocracia como Fator de Governança Pública no Instituto Federal de Educação do Mato Grosso. Revista Científica Multidisciplinar Núcleo do Conhecimento. Ano 03, Ed. 02, Vol. 04, pp. 05-18, Fevereiro de 2018. ISSN:2448-0959

\section{RESUMO}

Propõe-se analisar os princípios da meritocracia, visando orientar o aperfeiçoamento do sistema de mérito para a governança nos campi do Instituto Federal de Educação do Mato Grosso. Foi aplicado o instrumento de coleta em 19 campi agrupados para fins de análise em três grupos. Utilizou-se uma metodologia quali-quantitativa, aplicando técnicas de estatísticas inferencial, (alpha de Cronbach) e (teste Kruskal-Wallis e teste de Wilcoxon). A análise mostrou três fatores validados pelos gestores. Os princípios da meritocracia organizacional (MO) equidade, transparência e reconhecimento foram assimilados como fatores importantes para a governança. Concluiu-se que a transparência é o fator mais consolidado e institucionalizado e a equidade foi percebida como a mais importante, porém a que mais necessita ser estruturada pela gestão.

Palavras-Chave: Administração Pública, Gestão, Mérito, Meritocracia Organizacional.

\section{INTRODUÇÃO}

O contexto organizacional contemporâneo traz o tema relativo a meritocracia como tópico a ser estudo para melhoria da efetividade organizacional, temática que versa sobre a implantação de ambiente justo e orientado à geração de competências, habilidades e atitudes profissionais e não apenas para a competição pessoal. Essa concepção, tende a contribuir para a governança na perspectiva de elucidar os fatores meritocráticos.

Apesar de todos os esforços nem sempre as empresas estão satisfeitas com os recursos humanos de que 
dispõem, e vice-versa. A partir dessa constatação é que se constitui o desafio do mérito perante a governança, uma vez que os estudos nessa área buscam elucidar as variáveis capazes de produzir estímulos aos servidores. Busca-se, portanto, uma diversidade de meios para a produção de uma interação positiva do ponto de vista da governança.

A aplicação de um sistema de mérito nos campi do IFMT pode ser de grande relevância para o desenvolvimento da mesma. Para tanto, há de se considerar que se trata de uma organização prestadora de serviços de grande relevância sócio-cultural-econômica. Os campi do IFMT são organizações essencialmente prestadoras de serviços e têm como propósito atender as demandas educativas da sociedade, considerando principalmente os arranjos produtivos locais. Ainda deve-se ressaltar que administrar serviços é muito diferente de administrar produtos e a desconsideração desse fato nos processos de gestão pode acarretar diversos problemas relacionados à governança.

Enfim a meritocracia é concebida como um modelo de gestão para reconhecimento, cujos critérios a serem consideradas são o desempenho e os comportamentos individuais de cada pessoa. A meritocracia no contexto da governança está ligada à concepção de uma forma de estratégia para agregar, manter e desenvolver pessoas.

A problemática exposta traz um desafio emergente para a governança institucional que busca a conciliação entre satisfazer as expectativas das pessoas e os objetivos da organização, evidenciando assim a perspectiva da investigação do comportamento organizacional com a finalidade de elucidar critérios para verificação do mérito no exercício das atividades organizacionais.

Então, formula-se a questão orientadora: “As variáveis da meritocracia organizacional em que medida são percebidas como princípios para governança do Instituto Federal de Educação do Mato Grosso?”

$\mathrm{O}$ artigo tem como objetivo mensurar o reconhecimento dos princípios da meritocracia pelos gestores e o estágio atual que as variáveis são percebidas para a governança nos campi do Instituto Federal de Educação do Mato Grosso (IFMT).

\section{REFERENCIAL TEÓRICO}

O artigo apresenta fundamentos teóricos em relação a governança público e privada, assim como o contexto da aplicação dos fatores que envolvem a meritocracia nos estudos sobre a gestão nas organizações. Percebe-se que o modelo meritocrático é de difícil implementação, mas tem grande aderência e incidência as administrações seja do setor público ou privado que desejam a governança.

\subsection{A GOVERNANÇA CORPORATIVA: NATUREZA PRIVADA E PÚBLICA}

Lameira (2013) explica que em 1990 surgiu o termo "Governança Corporativa," nos Estados Unidos e na Grã-Bretanha, visando definir as regras de relacionamento entre acionistas controladores, minoritários e administradores. Em alguns países, como por exemplo Portugal, a Governança Corporativa surgiu recentemente devido à necessidade de atrair capitais e fontes de financiamento para a atividade empresarial, sendo acelerado pelo processo de globalização e a tendência de privatizações de empresas estatais. Em relação à terminologia existem muitas controvérsias, todavia para Arnold Wald a terminologia correta é "governo das empresas" pois, 
[...] caracteriza a sociedade anônima como corporação, tratando-se de anglicanismo condenável, não só por respeito à língua nacional como também pela associação de ideias que pode acarretar. Na língua portuguesa, corporação têm sentido de associação profissional, sendo inclusive uma reminiscência medieval [...] Acresce que os adjetivos corporativo e corporativista tem sentido pejorativo, dando ideia de prevalência de interesses de um grupo ou de uma classe. Ao contrário desta noção, o termo governança das empresas pretende denominar a renovação da entidade, atendendo aos interesses de todos aqueles que a integram ou com ela colaboram (WALD, 2015, p. 55).

A principal ênfase da Governança Corporativa está nas relações entre os stakeholders, acionistas e a alta administração, bem como os funcionários, fornecedores, clientes, bancos e outros credores, instituições reguladoras, o meio ambiente e a comunidade em geral, ou seja, a Governança Corporativa visa à regulamentação da estrutura administrativa da organização, por meio do estabelecimento dos direitos e deveres dos vários acionistas e da dinâmica e organização dos poderes. Suas abordagens múltiplas têm por finalidade garantir o equilíbrio dos principais participantes internos e externos da gestão em face aos interesses da organização, utilizando mecanismos que tentam reduzir ou eliminar os conflitos de interesse e as quebras do dever fiduciário visando alcançar uma estrutura de governança que resulte na valorização da companhia pelo mercado (CARDOSO, 2014).

Vários conceitos vêm aparecendo em relação à Governança Corporativa, quase todos centrados na visão de que governança corporativa compreende a estrutura de relacionamentos e correspondentes responsabilidades de acionistas, conselheiros e executivos, definidas estas da melhor maneira, de modo a encorajar as empresas a terem o desempenho econômico como objetivo principal (MILLSTEIN, 2011).

Na visão de Cardoso (2014) governança corporativa é o conjunto de relações entre o conselho de administradores de uma firma, seus acionistas e demais interessados, promovendo a estrutura pela qual os objetivos da firma são estabelecidos, os meios para alcançá-los e os critérios de mensuração da performance são determinados.

Para o Instituto Brasileiro de Governança Corporativa o conceito pode ser entendido como um sistema que assegura aos sócios a gestão estratégica da empresa e a efetiva monitoração da diretoria executiva. As boas práticas de governança asseguram equidade, transparência, responsabilidade pelos resultados e obediência às leis do país (IBGC, 2013).

De acordo com Carvalho (2007, p. 23) governança corporativa pode ser definida como "os mecanismos ou princípios que governam o processo decisório dentro de uma empresa". Os quatro princípios básicos que fundamentam as boas práticas de governança corporativa, de acordo com o IBGC (2010, p. 19), "são transparência, equidade, prestação de contas e responsabilidade corporativa".

Kissler (2006) aborda o tema questionando quais são as estruturas de governança do Estado e as diferenças entre a governança no setor público e privado, uma vez que conceitualmente o Estado tradicional vem se transformando, da seguinte forma:

a) Estado de serviço: produtor do bem público para um Estado que serve de garantia à produção do bem público;

b) Estado ativo: provedor solitário do bem público para um Estado ativador que aciona e coordena outros atores a produzir com ele; 
c) Estado gestor para um Estado cooperativo: produz o bem público em conjunto com outros atores.

A concepção de governança corporativa aplicada ao setor público é o resultado, segundo Bhatta (2003, p. 5-6), de uma nova administração das organizações do setor público por meio da aplicação dos princípios de governança corporativa do setor privado e, no seu entendimento, são totalmente aplicáveis às organizações do governo. A governança em geral possui similitudes aplicáveis entre as organizações públicas e as privadas, as quais são observáveis mediante os problemas em comum destes setores como, a título de exemplo, verificam-se as responsabilidades, o nível de poder, o monitoramento da execução das políticas e os objetivos planejados (IUDÍCIBUS, MARION, PEREIRA, 2003; LODI, 2000).

O setor público exerce papel primordial para a sociedade e as boas práticas na governança nesse setor podem contribuir para o uso eficaz dos recursos, com responsabilidade em prestar contas para o gestor dos mesmos e entrega dos serviços necessários, conseguindo atingir o objetivo das ações púbicas que é o bem-estar das pessoas (KISSLER; HEIDEMANN, 2006).

A governança ainda pode ser realizada por meio de redes de políticas públicas reconhecendo que as questões centrais de governo passam pelas interações de uma multiplicidade de atores do mercado, da sociedade civil organizada e dos órgãos do Estado, elaborando um composto definido como propício para obter resultado satisfatório (Kooiman, 1993, p. 174).

[...] redes de políticas públicas se auto-organizam. Trocando em miúdos, auto-organização quer dizer que as redes são autônomas e autogovernáveis [...], redes se desvinculam da liderança governamental, desenvolvem suas próprias políticas e moldam seus ambientes (Rhodes, 1997, p. 52).

Börzel (1998) informa que as redes de políticas públicas representam uma forma específica de interação entre atores públicos e privados. Por fim, a governança privada e pública tangem-se nas definições de poder e responsabilidades, propriedade e gestão e a garantia da execução de objetivos e políticas planejadas. A governança corporativa, em seu sentido originário, é aplicável às organizações, sejam mercantilistas, comunitárias, sem fins lucrativos e governamentais (LODI, 2000; FRANCO FILHO, 2003; MELLO, 2006).

Neste contexto, a governança no setor público deve tornar explícito o papel de cada agente, estabelecendo os seus objetivos, responsabilidades, modelos de decisão, processos, rotinas, dentre outras. Para MatiasPereira (2010), Gonzáles (2004) e Melo (2006), IFAC (2001) os princípios fundamentais na governança no setor público são:

- Transparência: é fundamental para garantir que a sociedade possa ter confiança no processo de tomada de decisão e nas ações das organizações do setor público, na sua gestão e nas pessoas que nela trabalham;

- Integridade: relativo a ações honestas e justas. É baseada na honestidade, objetividade, normas de propriedade, probidade na administração dos recursos públicos;

- Equidade: adoção de um sistema de justiça e oportunidade para os stakeholders conforme o grupo que o mesmo participa;

- Responsabilidade de prestar contas: as organizações do setor público e seus indivíduos são responsáveis por suas decisões e ações e, principalmente na administração dos recursos públicos e devem apresentar seu resultado. 
Os princípios articulados acima podem ser considerados oriundos ou desdobrados do marco constitucional de 1988 que demarca o estado democrático de direito que se implantou a partir de então, estabelecendo o controle sobre a administração pública por meio da integridade, transparência e prestação de contas, bem como da participação direta na escolha das políticas públicas a serem implantadas (BRASIL, 1988).

Os países em que essa revolução [gerencial] foi mais profunda foram o Reino Unido, a Nova Zelândia e a Austrália. Nos Estados Unidos essa revolução irá ocorrer principalmente no nível dos municípios e condados - revolução que o livro de Osborne e Gaebler, Reinventando o Governo (1992) descreverá de forma tão expressiva. É a administração pública gerencial que está surgindo, inspirada nos avanços realizados pela administração de empresas (BRESSER-PEREIRA, 1996, p. 5).

A comunidade epistêmica de administração pública tem discutido intensamente sobre o papel do Estado no contexto da Nova Gestão Pública, considerando seu papel de protagonismo. Kooiman (1993) indica uma tendência de se reduzir a participação do Estado no processo de elaboração de políticas públicas, uma vez que a Nova Gestão Pública abre espaço para o envolvimento de atores não estatais no planejamento e implementação das mesmas, gerando um novo processo de atuação múltipla nas políticas. Rhodes (1997, p. 57) confirma essa tendência com a assertiva de que "o Estado torna-se uma coleção de redes interorganizacionais compostas por atores governamentais e sociais sem nenhum ator soberano capaz de guiar e regular". Bresser-Pereira (2006), compartilhando a mesma visão, entende que a burocrática dominante deve ser transformada com uma nova cultura gerencial voltada para resultados com base nas ferramentas das corporações privadas.

\subsection{FUNDAMENTOS DA MERITOCRACIA}

A palavra "meritocracia" é originária do latim meritum e do sufixo grego ????? (-cracía) e significa poder do mérito, configurando uma forma de premiar-se o mérito de alguém. Em 1958, Michael Young cunhou o termo "meritocracia" em seu livro, "The Rise of a Meritocracia" (BARBOSA L., 2002). Ele usou o termo para descrever satiricamente o Reino Unido governado por um sistema que favoreceu inteligência e mérito acima de tudo e todos, incluindo realizações pessoais passadas (BARBOSA L., 2006).

No entanto, o conceito de meritocracia assumiu um significado diferente. Agora se refere às organizações em que as melhores pessoas ganham. Já não é uma ideia ridicularizada, mas sim comemorada. Na verdade, uma empresa que pretende construir e fomentar o engajamento entre seus colaboradores, bem como incentivar a liderança deve considerar a adoção de uma abordagem meritocrática (BARROS; PRATES, 2006). A meritocracia é considerada um modelo de governança baseada no mérito das pessoas, em que o merecimento está associado à educação e à competência (BARBOSA L., 1999).

Do ponto de vista formal e jurídico, a sociedade brasileira, de um modo geral, e o serviço público, de forma particular, encontram-se, sem dúvida alguma, organizados como um sistema meritocrático, tanto para o ingresso quanto para a mobilidade no seu interior. Entretanto, a leitura da 'realidade empírica' pelos diferentes segmentos sociais envolvidos nesse debate - elites políticas, intelectuais e servidores públicos - não ratificam o Brasil como uma sociedade ideologicamente meritocrática (BARBOSA L., 1999, p. 70). 
O que é uma meritocracia no local de trabalho? Em uma meritocracia, todos têm direito de expressar suas opiniões e são incentivados a compartilhá-las abertamente. Essas opiniões são ouvidas e as decisões são tomadas com base naquelas que são consideradas as melhores. É importante entender que a meritocracia não é uma democracia. Não há "decisão por consenso"; nem toda a gente tem um voto. Esta é a principal diferença da meritocracia. Enquanto todo mundo tem uma voz, alguns são ouvidos mais do que outros (BARBOSA L. 2002, BARBOSA L. 2009; BARROS; PRATES, 2006).

Aqui reside o ponto crucial de uma meritocracia: quem decide quem vai ser ouvido? Quem decide quais as ideias são as melhores? Na empresa, Red Hat, por exemplo, as pessoas que são ouvidas são aquelas que ganharam esse direito. Eles construíram uma reputação e histórico por contribuírem com boas ideias, indo além de seus trabalhos cotidianos e alcançaram resultados estelares (BARROS; PRATES, 2006).

Em muitas empresas de tecnologia que empregam um sistema de meritocracia - como na Red Hat - onde as pessoas forjam seu próprio caminho para a liderança, não simplesmente por trabalharem duro, mas também por expressarem ideias originais que têm a capacidade de impactar positivamente tanto a equipe quanto a empresa. Na Red Hat (principal fornecedor mundial de soluções de software open source), pessoas são incentivadas a terem iniciativa e gerar novos caminhos para a organização, com isto, elas ganham bastante confiança e respeito dos companheiros de equipe. Conclui-se que para as pessoas poderem ser ouvidas, o resultado de suas ações é importante para influenciar tanto a direção da empresa, mas também as pessoas da equipe (BARROS e PRATES, 2006).

\subsection{A CULTURA ORGANIZACIONAL E A MERITOCRACIA}

A ideia de cultura organizacional é algo bem popular, mas sua definição precisa é controversa na literatura. Para Vecchio (2012):

Cultura organizacional tem sido definida, sob diversas formas, como sendo uma filosofia subjacente à política de uma organização, às regras do jogo para continuar operando e à sensação ou ao clima transmitido pelo layout físico da organização. Outros propõem que a cultura organizacional é, em grande parte, uma questão de normas (p. 340).

Schein (2002) conota a cultura organizacional como sendo pressupostos básicos que um grupo inventou, descobriu ou desenvolveu ao aprender lidar com os problemas institucionais e funcionaram satisfatoriamente para serem considerados válidos e ensinados a novos membros.

Romero-Garcia (1991) ensina que cada indivíduo possui crenças, atitudes, valores e qualidades de comportamento que o posicionam como membro do que ele chamou de cultura maior ou menor. A primeira, no entendimento deste autor, é a cultura da sociedade em geral, tendo em vista o indivíduo médio, representante da população de um país em vias de desenvolvimento, já a segunda diz respeito à cultura industrial e empresarial, tida como desenvolvida e característica de indivíduos mais capacitados pessoal e profissionalmente.

Para Barney (1986, p. 657) cultura organizacional é tipicamente definida como "um conjunto complexo de valores, crenças, hipóteses e símbolos" que orientam o comportamento dos membros da organização (Hofstede et al., 1990) e impacta no intercâmbio do conhecimento, a interação e o valor percebido dos membros da organização (TSENG, 2010). 
Pode-se observar no modelo para estudar a cultura organizacional proposto por Souza (1978) que o mesmo possui três elementos básicos: preceitos, tecnologia e caráter. Preceitos, o autor sugere como a autoridade e o conjunto de regulamentos e valores, explícitos ou implícitos, que regem a vida organizacional, estando inclusos a política organizacional, costumes sociais, estilos de gerência, rituais e cerimoniais, tabus, tradições, dogmas, sanções e padrões de conduta esperada.

Já a tecnologia pressupõe como o conjunto de ferramentas e processos empregados no trabalho organizacional, inclusive em suas relações com o ambiente externo. Assim, têm-se equipamentos, máquinas, divisão de tarefas, estrutura de funções, recursos materiais, cronograma, redes de comunicação, metodologia de serviços, dentre outros. Já caráter é conceituado como o conjunto das manifestações afetivas espontâneas dos indivíduos que compõem a organização, tais como alegria, tristeza, apatia e medo.

Percebe-se que a cultura organizacional tem um alto componente de especificidade, ou seja, a cada organização pelo conjunto de fatores que a envolve e as pessoas que dela participam terá uma moldagem cultural própria que influenciará o estudo da meritocracia. Neste sentido, mas de uma forma ampla, Newstrom (2008, p. 392) explica que "contingência cultural significa que as práticas mais produtivas para determinada nação dependerão essencialmente de sua cultura".

Essas normas e valores são transmitidos de uma pessoa para outra por meio dos elementos superficiais da cultura, indicam a necessidade de estudos contínuos de temas relativos a meritocracia e as ferramentas para o aumento dos resultados organizacionais, visando estabelecer e controlar metas individuais e alinhar os resultados alcançados com o plano estratégico da instituição (BARBOSA L., 2014).

Bilhim (2013, p. 215) informa que "a meritocracia tem acompanhado a história da administração pública e, recentemente, a sua importância foi reforçada pela cartilha reformista da nova gestão pública - New Public Management (NPM). Importante ressaltar que mesmo com advento dos novos pilares da NPM o valor que Max Weber atribuía à meritocracia permaneceu.

A questão da recompensa por mérito desejado pelas organizações é um fator difuso e específico, segundo Régnier (2007), que tem sofrido transformações na substância a partir da perspectiva das organizações; esta constatação originou-se a partir de sua pesquisa analisando os anúncios de classificados de empregos visando à contratação de gerentes e executivos. A oferta direcionada aos profissionais geram incertezas quanto ao tipo de atributos do profissional buscado pelas empresas pesquisadas.

O desenho do perfil dos candidatos do ponto de vista do mérito para seleção é complexo, tanto no que diz respeito à formação educacional como em relação à trajetória profissional e de determinadas capacidades e competências exigidas para os cargos à serem ocupados nas organizações (Régnier, 2007).

Apesar da incerteza do perfil desejado a implantação da cultura de meritocracia não pode ser entendida como uma ação impossível, para tanto deve-se compatibilizar no ambiente organizacional a valorização do comportamento humano e considerar seus fatores influentes como elementos para o alcance dos resultados.

O principal argumento em favor da Meritocracia é que ela proporciona maior justiça do que outros sistemas de avaliação e premiação, uma vez que as distinções não se dão por sexo ou raça, nem por 
riqueza ou posição social, entre outros fatores biológicos ou culturais. Embora genericamente a Meritocracia seja um consenso, existem várias divergências acerca deste princípio no momento da sua aplicação prática (Barddal et al., 2008, p. 28).

A resistência à aplicação da meritocracia nas práticas organizacionais públicas é justificada de diversas maneiras como a dificuldade de medir o trabalho não repetitivo, a falta de meios que assegurem a equidade entre avaliadores e a organizações, a arbitrariedade e a subjetividade do processo de tomada de decisão, dentre outros (Bilhim, 2013).

\section{PROCEDIMENTOS METODOLÓGICOS}

Para cumprir com os objetivos da pesquisa foi empreendida um estudo do tipo quantitativo estatístico (Cooper; Schindler, 2003), aplicando na pesquisa de campo o método survey (Creswell, 2017), com relação a análise do problema, optou-se por uma abordagem mista combinado a qualitativa e quantitativa.

A abordagem quantitativa predominou em função das características de dispersão geográfica e necessidade de mensuração da consensualidade da população pesquisada, formada pelos gestores dos campi do IFMT nas funções de direção geral, ensino e administração.

Com a obtenção da autorização e apoio da reitoria, foi disponibilizada a lista de todos os gestores com contatos de e-mail e telefone dos campi. A partir da análise destes dados foi elaborada uma estratégia de comunicação e realizado o envio de uma mensagem informando os objetivos e a relevância da pesquisa aos gestores dos campi, solicitando-lhes a autorização para a realização da pesquisa, bem como a colaboração com a resposta das questões e no e-mail continha o link do questionário elaborado no sistema online LimeSurvey. Os respondentes ao obterem o conhecimento do processo e ao aceitarem colaborar com a pesquisa, acessavam o link enviado por e-mail que também continha uma senha de acesso privado ao instrumento de coleta online.

A população era composta por 52 gestores em 19 campi, o que mostrou ser mais promissor a opção pelo levantamento censitário, que obteve a devolutiva de $60 \%$ da população, compondo uma amostra não probabilística, que compreendeu a heterogeneidade de maneira significativa do universo em estudo, favorecendo a operacionalização da estatística (Lakatos; Marconi, 2017).

Importante salientar que a pesquisa se valeu da estratégia de estudo multicaso (Yin, 2015), sendo dezenove campi integrantes do Instituto Federal de Educação do Mato Grosso no ano de 2017, agrupados em 3 grupos em função de características e realidades distintas tais como: GRUPO 01 - Campus implantado ou em implantação (em atividade) antes lei federal 11.892/2008. Campi: Bela Vista, Cárceres, Campo Novo do Parecis, Cuiabá, Pontes e Lacerda e São Vicente; GRUPO 02 - Campus implantado após a lei federal 11.892/2008. Campi: Alto Floresta, Confresa, Barra do Garças, Juína, Primavera do Leste, Sorriso, Rondonópolis e Várzea Grande; e GRUPO 03 - Campus Avançado implantado após a lei federal 11.892/2008. Campi: Diamantino, Guarantã do Norte, Lucas do Rio Verde, Sinop e Tangará da Serra.

O questionário de coleta de foi dividido em duas seções distintas. A escolha de um método online considerou critérios relativos a custo, tempo e conformidade de resposta para o estudo, configurando questões fundamentais para escolha desta estratégia de aplicação via internet (Freitas et. al, 2000). A 
primeira seção coletava dados gerais sobre o perfil dos participantes da pesquisa, e a segunda as variáveis de estudo.

A validação da ferramenta de coleta de dados foi realizada um pré-teste com os participantes da pesquisa, cerca de $17 \%$ da população estudada, objetivando-se corrigir falhas, redação e concepções e aperfeiçoando as questões. Com a avaliação das incongruências e as devidas correções, o questionário foi aplicado utilizando o sistema on-line LimeSurvey durante o período de janeiro à março de 2017.

O tratamento dos dados foi desenvolvido em etapas: (a) codificação dos questionários para facilitar o acesso e vinculação da resposta ao grupo de campi; (b) tabulação dos dados; (c) análise preliminar dos dados para as medidas descritivas; (d) avaliação da adequação da amostra, do método de extração dos fatores; e, (e) exploração dos dados através das análises estatísticas (Lakatos; Marconi, 2017; Cooper; Schindler 2003; Creswell, 2017).

Em uma análise preliminar na fase de tabulação dos dados, detectou-se que havia 8 questionários comprometidos em função do número excessivo de dados perdidos, tornando sua análise inviável, o que levou à tomada de decisão pela exclusão destes do banco de dados válido.

$\mathrm{Na}$ exploração dos dados, para atender aos objetivos da pesquisa, utilizou-se o software livre $R$ project, versão 3.3.1, 2016 da The $R$ Foundation for Statistical Computing, onde calculou-se alpha de Cronbach para verificar a confiabilidade das variáveis - instrumento de pesquisa - e a correlação entre elas determinada através da análise fatorial exploratória. O teste Kruskal-Wallis, determinou a comparação entre os grupos de campi para determinar suas similitudes e o teste de sinal de Wilcoxon para testar as hipóteses de pesquisa.

Foram analisadas para este artigo as variáveis da meritocracia extraídos da literatura especializada. Após a etapa de análise dos dados com as técnicas estatísticas, os mesmos foram cruzados com os dados qualitativos para contemporização e configuração final das informações. Na etapa qualitativa foram selecionados os informantes chave, utilizando o critério de acessibilidade e tipicidade (Cooper; Schindler, 2003, p. 169).

\section{ANÁLISE DOS DADOS E RESULTADOS}

A população participante foi composta por 31 respondentes, com maioria do sexo masculino (55\%), a função predominante foi diretor ou chefe de ensino (39\%), seguido de Diretor de Administração e Planejamento ou Responsável pelo Setor Administrativo (35\%), o tempo médio de serviço deles é de 6 anos e 4 meses (tabelas 1).

Tabela 1 - Descrição do tempo de serviço dos gestores

\begin{tabular}{|c|c|c|c|}
\hline Variável & Categoria & Anos & Meses \\
\hline Tempo Médio de & Grupo 1 & 6 & 11 \\
Serviço dos gestores. & Grupo 2 & 5 & 7 \\
& Grupo 3 & 6 & 5 \\
\hline
\end{tabular}




\section{FONTE: Dados obtidos na pesquisa de campo (2017)}

Os gestores dos Campi avançados apresentam uma média de tempo de serviço superior ao Grupo 2 que é composto por campi mais antigos e já implantados, tal fato pode ser explicado em função de que esses gestores são pro tempori (nomeados pelo reitor). Desta forma, como compõem projetos de expansão da estrutura, a reitoria buscou nomear servidores com experiência e vivência dentro IFMT. O Regimento Geral do IFMT estabelece normas para suprir o cargo de Diretor-Geral nos campis, seja em fase de implantação ou não:

Art. 117. Os campi do Instituto Federal de Mato Grosso serão administrados por Diretores-Gerais escolhidos pelos servidores e discentes, em processo democrático e nomeados de acordo com o que determina a legislação vigente.

- $1^{\circ}$. Nos campi em processo de implantação, os cargos de Diretor-Geral serão providos em caráter "Pro Tempore", por nomeação do Reitor, até que seja possível identificar candidatos que atendam aos requisitos previstos na legislação vigente (BRASIL, 2012).

A confiabilidade estatística das questões aplicadas aos respondentes foi confirmada a partir do cálculo do coeficiente alpha de Cronbach de acordo com os limites apresentados por Freitas e Rodrigues (2005). Assim a análise da confiabilidade dos aspectos descritos na tabela 2, para tanto foi calculado o alpha de Cronbach das questões sobre os princípios MO, dispostos na tabela 3.

$\mathrm{Na}$ pesquisa em tela dentro de uma perspectiva geral, pode-se dizer que as perguntas de um mesmo aspecto mensurado são de fato consistentes uma vez que os valores de alpha de Cronbach foi acima de 0.75. O alpha de Cronbach geral foi de 0.90 que é um valor alto [2], indicando que o instrumento produz mensurações estáveis e consistentes [2].

Tabela 2 - Alpha de cronbach

\begin{tabular}{|c|c|c|}
\hline Quesitos & Aspectos & Alpha de Cronbach \\
\hline Princípio MO & EQUIDADE & 0.89 \\
\hline & RECONHECIMENTO & 0.92 \\
\hline & TRANSPARÊNCIA & 0.89 \\
\hline Geral & & 0.90 \\
\hline
\end{tabular}

\section{FONTE: Dados obtidos na pesquisa de campo (2017)}

Os aspectos mais importantes que obtiveram maior média de pontuação nos testes estatístico (tabela 3) foram a variável equidade, seguida da transparência e reconhecimento. As análises foram realizadas a partir do cálculo das médias das variáveis do constructo da meritocracia organizacional bem como a aplicação do teste que verifica a importância do constructo estabelecendo se é relevante para os respondentes através do teste do sinal (observando p-valor) e também a comparação das médias com o ponto de corte, o ponto de referência (3) da escala likert, de cada obtida por cada aspecto, conforme feito 
na tabela 3.

Tabela 3 - Média, mediana, desvio padrão das pontuações médias geradas a partir das questões seguido do p-valor do teste do sinal para localização no ponto de corte 3

\begin{tabular}{|c|c|c|c|c|c|c|c|c|}
\hline Quesitos & Aspectos & Média & Mediana & $\begin{array}{c}\text { Desvio } \\
\text { padrão }\end{array}$ & \multicolumn{2}{|c|}{ IC (95\%) } & p-valor & \\
\hline $\begin{array}{c}\text { Princípios } \\
\text { MO }\end{array}$ & Equidade & 4.0 & 4.0 & 0.4 & 3.8 & 4.2 & $<.0001$ & \\
\hline $\begin{array}{c}\text { Reconheci } \\
\text { mento }\end{array}$ & 3.9 & 3.9 & 0.5 & 3.7 & 4.1 & $<.0001$ & \\
\hline $\begin{array}{c}\text { Transparên } \\
\text { ncia }\end{array}$ & 3.9 & 4.0 & 0.4 & 3.8 & 4.1 & $<.0001$ & \\
\hline
\end{tabular}

FONTE: Dados obtidos na pesquisa de campo (2017).

A preocupação institucional com a transparência pode ser confirmada pela exposição de Barbosa $\mathrm{J}$. (2016) sobre o tema:

"O grande legado que deixo mesmo é a expansão e a normatização do Instituto. Agora o futuro Reitor tem que consolidar essa expansão e continuar com a normatização que iniciei, deixando a Instituição mais transparente possível, acho que quanto mais transparente for a Instituição melhor para os servidores, para sociedade, para os nossos alunos e enfim para todo mundo.“

A importância da transparência para a governança corporativa pública do IFMT pode ser constatada nos seguintes dizeres do reitor:

[...] a partir do momento que você cria normas e que você deixa muito claro para o seu servidor, para o seu aluno e para sociedade o que você tem que fazer para você chegar em determinado ponto, então acho que isto é muito importante, que o professor chegue e saiba como fazer para sair para uma pós-graduação, ou seja, sabe o que tem que fazer hoje e por isto nós fizemos toda normatização para garantir. Antes as pessoas não sabiam quem poderia sair e porque não poderia sair todo mundo. Por isso nós elaboramos o RASAC, que é um documento que fala quem pode se afastar e quem não pode sair para pós-graduação, tanto os técnicos administrativos e os professores (BARBOSA J., 2016).

Para enfatizar essa percepção institucional Assaf Neto (2014) apresenta o resultado de uma pesquisa realizada pelo Banco Mundial, com investidores, visando identificar quais fatores induziam valor às companhias com as boas práticas de Governança Corporativa. Verificou-se que os investidores até $28 \%$ a mais por ações de empresas que adotam melhores práticas de gestão e transparência. Bull (apud GÓMEZ, 2011, sp), afirma que "vale a pena ressaltar que a meritocracia só funciona se houver regras claras e transparentes”, fica evidente que a transparência é um dos princípios básicos para as boas práticas em governança corporativa (IBGC (2010, p. 19). 
Vale ressaltar que o IFMT está em fase de consolidação não somente de métodos de governança, mas das melhores práticas de gestão em função da sua expansão física dispersa geograficamente no Mato Grosso.

[...]as nossas Pró-Reitorias e da gestão Geral do Instituto está consolidada, porém nós temos alguns campi que ainda não está consolidada, nós temos um trabalho forte pela frente para fazer, tanto é que nós tivemos a eleição agora no último dia 7 de dezembro de 2016, nós já acertamos com meu sucessor que foi o meu candidato, no qual apoiei, que nós vamos lá começar já em janeiro, um grande planejamento com a capacitação de todos os diretores eleitos. Porque a posse dos novos diretores deverá ser em abril do próximo ano ou maio, nós queremos preparar todos os diretores gerais e diretores do Instituto para fazermos um planejamento estratégico preparando essa nova gestão do Instituto Federal do Mato Grosso, porque nós temos ainda algumas deficiências em alguns Campi. Nossos dirigentes não sabem delegar e não sabem fazer uma série de atividades. Então esse é um trabalho que nós vamos fazer agora no início do ano de 2017 para quando em abril ou maio as pessoas que vão assumir a gestão nas unidades do Instituto Federal do Mato Grosso possam ser mais profissionais em seu caminho, nós queremos trilhar e avançar ainda mais com a nova gestão da Instituição e com a gestão dos campi (BARBOSA J., 2016).

A análise final busca-se estabelecer os fatores de congruência e discrepância em relação aos grupos de campi através da comparação entre eles realizada através do teste de Kruskal-Wallis. Observa-se que de fato foi detectado que existem algumas diferenças entre os grupos de campi, podendo ser percebido com a verificação dos aspectos cuja diferença entre as variáveis ocorre com a apresentação do p-valor menor do que (0.05) no teste aplicado.

\begin{tabular}{|c|c|c|c|c|c|c|c|c|c|c|c|}
\hline \multirow{3}{*}{ Quesitos } & \multirow{3}{*}{ Aspectos } & \multicolumn{9}{|c|}{ Campi } & \multirow{3}{*}{ p-valor } \\
\hline & & \multicolumn{3}{|c|}{ Grupo 1} & \multicolumn{3}{|c|}{ Grupo 2} & \multicolumn{3}{|c|}{ Grupo 3} & \\
\hline & & Média & Mediana & $\begin{array}{l}\text { Desvio } \\
\text { padrão }\end{array}$ & Média & Mediana & $\begin{array}{l}\text { Desvio } \\
\text { padrão }\end{array}$ & Média & Mediana & $\begin{array}{l}\text { Desvio } \\
\text { padrão }\end{array}$ & \\
\hline & Equidade & 4.1 & 4.1 & 0.3 & 3.8 & 3.8 & 0.4 & 4.2 & 4.1 & 0.4 & 0.049 \\
\hline $\begin{array}{c}\text { Princípios } \\
\text { MO }\end{array}$ & Reconhecimento & 4.1 & 4.1 & 0.5 & 3.7 & 3.8 & 0.5 & 4.0 & 4.1 & 0.6 & 0.169 \\
\hline & Transparência & 4.1 & 4.1 & 0.4 & 3.8 & 3.8 & 0.4 & 4.0 & 4.1 & 0.4 & 0.081 \\
\hline
\end{tabular}

Tabela 4 - Média, mediana e desvio padrão das pontuações médias geradas a partir das questões seguido do p-valor do teste de Kruskal Wallis para comparação entre grupos. FONTE: Dados obtidos na pesquisa de campo (2017).

Com os resultados, observa-se que de fato existem algumas diferenças entre os grupos de campi, com base no p-valor menor do que (0.05) no teste aplicado. Constatou-se então, que o princípio de equidade em MO (p-valor 0.0498) tem sua percepção de importância distinta entre os grupos de campi, sendo que o grupo 2 apresentou menor pontuação (média de 3.8) e o grupo 3 maior pontuação (4.2). A equidade é um princípio que demonstra ser relevante, mas não se tem uma uniformidade sobre a forma de implementação e gestão dentro do IFMT na perspectiva dos gestores dos campi.

\section{CONSIDERAÇÕES FINAIS}

A pesquisa no que tange os princípios propostos sobre o mérito na organização (equidade, transparência e reconhecimento) mediante extração empírica da literatura especializada, obtive a validação pelos gestores 
por meio das técnicas estatísticas aplicadas. Os princípios da Meritocracia Organizacional relativos a transparência e reconhecimento percebidos foram ponderados com o mesmo peso pelos campi dos Grupos 1, 2 e 3, divergindo somente sobre a percepção do aspecto equidade. Ao verificar que esse mesmo princípio também foi apontado como de maior relevância pelos gestores dos campi, indicando que não existe uma uniformidade na percepção dos grupos neste item, apesar de sua grande relevância ter sido atestada.

Constatou-se que o estágio atual dos princípios MO são diferentes, sendo que a equidade é a mais valorada e as demais tem semelhante peso, porém na prática a transparência tem sido o principal foco de atenção no IFMT, com tais verificações atende-se ao objetivo geral proposto neste trabalho.

Como limitação do estudo, tem-se a abrangência do quadro teórico a partir da análise da literatura especializada baseada na percepção do pesquisador e apresentadas aos gestores dos campi do IFMT. Neste sentido, é factível que a percepção de alguns deles seja afetada pelas experiências pessoais/profissionais sobre meritocracia organizacional dominante no ambiente de trabalho que atua ou já atuou.

Conclui-se que apesar das preocupações relativas a todo os princípios da meritocracia em geral, mais especificamente à equidade na percepção dos gestores dos campi ganha destaque, contrastando com as ações da reitoria que se mostrou mais focada no aspecto do fortalecimento da transparência na Instituição. Estes resultados permitem deduzir que além de ações relativas à transparência, o IFMT precisa também desenvolver práticas relativas ao aspecto equidade no sistema de mérito para os servidores. A literatura especializada abordada neste artigo indica que deve-se investir nessa construção, uma vez que ficou evidenciado no referencial teórico que a cultura da meritocracia é uma realização a longo prazo que demanda muita persistência em sua implantação e consolidação.

\section{REFERÊNCIAS}

Assaf Neto, Alexandre. (2014). Finanças corporativas e valor. São Paulo: Atlas.

Barbosa J., B., (2016). Entrevista: governança e mérito do comportamento no IFMT. Cuiabá, Reitoria do IFMT.

Barbosa, L. (1996). Meritocracia à brasileira: o que é desempenho no Brasil?. Revista do Serviço Público, a. 47, v. 120, n. 3.

(2002). Cultura e empresas. 1.ed. Rio de Janeiro: Jorge Zahar Editor.

(2006). O Jeitinho brasileiro. Rio de Janeiro: Elsevier.

(2009) Igualdade e meritocracia. 2. ed. Rio de Janeiro: Editora FGV.

(2014). Meritocracia e a sociedade brasileira. Revista de Administração de Empresas, vol. 54, $\mathrm{n}^{\mathrm{o}}$ 1. São Paulo: FGV, Janeiro/Fevereiro.

BARNEY, J.B. (1986) Organizational culture: can it be a source of sustained competitive advantage. 
Academy of Management Review, Vol. 11 No. 3, pp. 656-65.

BARROS, B.T.; PRATES, M.A.S. (2006) O estilo brasileiro de administrar. São Paulo: Atlas.

BHATTA, Gambhir. (2003) Post- NPM Themes. In: Public Sector Governance, Wellington: State Services Commission. Working Paper no. 17. Sept. Acesso em: 16 dez. 2015.

Bilhim, J. (2013). Papel dos Gestores na Mudança cultural da Administração Central do Estado: o caso da meritocracia Passagens. Revista Internacional de História Política e Cultura Jurídica, vol. 5, n. 2, maio-agosto, pp. 205-227.

BÖRZEL, Tanja. (1998) Le reti di attori pubblici e privati nella regolazione europea. Stato e Mercato, v. 54, n. 3, p. 389-432.

BRASIL (1988) Constituição Federal de 1988. Brasília: DF.

(2012) Regimento Geral. Vigência 2012. IFMT. Cuiabá/MT.

BRESSER PEREIRA, L.C. (1996) Da administração pública burocrática à gerencial. Revista do Serviço Público, v.120, n.1.

(2006) Da administração pública burocrática à gerencial. Rio de Janeiro:

FGV.

CARDOSO, Ricardo L. (2014) Governança Corporativa ou Gerenciamento de Resultados? São Paulo: Conselho Federal de Contabilidade-CFC, n. ${ }^{\circ}$ 164, nov./dez..

CARVALHO, A. G. (2007) Governança Corporativa no Brasil em Perspectiva. In: CARVALHO DA SILVA, A. L.; LEAL, R. P. C. (Org.). Governança Corporativa - Evidências Empíricas no Brasil. São Paulo: Atlas.

Cooper, D. R.; Schindler, P. S. (2003). Métodos de pesquisa em administração. 7. ed. Porto Alegre: Bookman.

Creswell, John W. (2017). Research Design: Qualitative, Quantitative, and Mixed Methods Approaches. SAGE Publications.

FRANCO FILHO, J.R. (2003) Governança organizacional aplicada ao setor público. In: Congresso Internacional Del CLAD sobre la Reforme del Estado y de la Administración Pública, VIII, Panamá. Anales, Panamá, 28-31 Oct.

Freitas, H., Oliveira, M., Sacol, A. Z., Moscarola, J. (2000). O método de pesquisa survey. Revista de Administração, São Paulo, v. 35, n.3, p. 105-112, julho/setembro.

Gómez, N. (2011) Meritocracia: em busca da recompensa. Melhor - Gestão de Pessoas: Revista Oficial da ABRH-Nacional, São Paulo, n. 281, abril. 
GONZALEZ, R. (2004) Governança e Comunicação na Responsabilidade Social Empresarial. Relação com Investidores. IMF Editora.

Hofstede, G., Neuijen, B., Ohayv, D. D.; Sanders, G. (1990). Measuring organizational cultures: A qualitative and quantitative study across twenty cases. Administrative Science Quarterly, 35, 286-316.

IBGC - Instituto Brasileiro de Governança Corporativa. (2010) Código das melhores práticas de governança corporativa. São Paulo IBGC. Acesso em 05 jan. 2016. Disponível em: www.ibgc.org.br.

IBGC - Instituto Brasileiro de Governança Corporativa. (2013) Governança Corporativa. Acesso em 05 jan. 2016. Disponível em www.ibgc.org.br.

IFAC. International Federation of Accountants. (2001) Governance in the Public Sector: A Governing Body Perspective. Study 13. 2001. Acesso em: 27 jan. 2016. Disponível em <http://www.ifac.org>.

IUDÍCIBUS, S. de; MARION, J. C.; PEREIRA, E. (2003) Dicionário de Termos de Contabilidade. $2^{\mathrm{a}}$ Ed. São Paulo: Atlas.

KISSLER, L; HEIDEMANN, F.G. (2006) Governança pública: novo modelo regulatório para as relações entre Estado, mercado e sociedade. Revista da Administração Pública, Rio de Janeiro vol. 40, n. ${ }^{\circ}$, maio/jun.

KISSLER, L; HEIDEMANN, F.G. (2006) Governança pública: novo modelo regulatório para as relações entre Estado, mercado e sociedade. Revista da Administração Pública, Rio de Janeiro vol. 40, n. ${ }^{\circ}$, maio/jun. Acesso em: 27 jan. 2016.

Kooiman, J. (1993). Modern governance: new government-society interactions. Newbury Park, Calif.: Sage.

Lakatos, E. M.; Marconi, M. A. (2017). Metodologia Científica. São Paulo, Atlas.

LAMEIRA, V.J. (2013) Governança Corporativa. Rio de Janeiro; Forense Universitária.

LODI, João Bosco. (2000) Governança Corporativa: o governo da empresa e o conselho de administração. $7^{\mathrm{a}}$ reimpressão. Rio de Janeiro: Elsevier.

MATIAS-PEREIRA, José. (2010) Governança no setor público. São Paulo: Atlas.

MELlO. G.R. (2006) Governança Corporativa no Setor Público Federal Brasileiro. 127 f. Dissertação (mestrado em Ciências Contábeis). São Paulo: FEA/USP.

MILLSTEIN, Ira M. (2011) Governança Corporativa. Rio de Janeiro; Forense Universitária.

Newstrom, J. W. (2008). Comportamento organizacional: o comportamento humano no trabalho. $12^{a}$ edição. São Paulo: McGraw-Hill. 
Régnier , Karla von Dollinger (2007) O que conta como mérito no processo de pré-seleção de gerentes e executivos no Brasil. Caderno CRH. Vol. 20 n 49 Salvador Jan./Apr.

RHODES, Roderick A. W. (1997) Understanding governance: policy networks, governance, reflexivity, and accountability. Buckingham, Philadephia: Open University Press.

ROMERO-GARCIA, O. (1991) Crecimiento Psicológico y Motivaciones Sociales. Mérida, Venezuela: Rogya.

Schein, Edgar. H. (2002). Defining organizational culture. In: Schein, E. H. Organizational Culture and Leadership. San Francisco: Jossey-Bass Publishers.

SOUZA E. L. P. (1978) Clima e cultura organizacionais: como se manifestam e como se manejam. São Paulo: Edgard Blucher.

Tseng Shu?Mei, (2010) The correlation between organizational culture and knowledge conversion on corporate performance. Journal of Knowledge Management, Vol. 14 Iss: 2, pp.269 - 284.

Vecchio, Robert P. (2012). Comportamento organizacional: conceitos básicos. Tradução: Roberto Galman. São Paulo: Cengage Learming.

WALD, Arnold. (2015) O Governo das Empresas. São Paulo: Rev. Dir. Bancário Mercado de Capitais e da Arbitragem.

Yin, R. K. (2015). Estudo de caso: planejamento e métodos. 5. ed. Porto Alegre: Bookman, 320 p.

[1] Doutorando em Administração pela Universidad de la Empresa (UDE), Uruguai. Mestre em Administração UDE, Especialista em Gerenciamento de Micro e Pequenas Empresas pela Universidade Federal de Lavras, bacharel em Administração pela Faculdade de Ciências Administrativas de Curvelo. Atualmente Vice-Presidente do Conselho Regional de Administração de Goiás e Professor efetivo do Instituto Federal de Educação Goiano.

[2] Doutorado em Administração Universitária pela The George Washington University. Mestrado em Administração pela Universidade Federal do Rio Grande do Sul. Graduação em Administração pela Universidade Federal do Rio Grande do Sul. Graduação em Administração Pública pela Universidade Federal do Rio Grande do Sul. Professor Titular Aposentado da Universidade Federal de Santa Catarina onde exerceu as seguintes funções: Coordenador do Curso de Mestrado em Administração; Diretor do Instituto de Pesquisa em Administração Universitária; Coordenador de Cursos de Mestrados em Administração Interinstitucionais; Chefe de Departamento do Curso de Ciências da Administração. Professor da Universidade Alto Vale do Rio do Peixe (UNIARP). É professor convidado do Curso de Doutorado em Administração da Universidad de la Empresa de Montevideo (UDE), Uruguai.

\section{PUBLIQUE SEU ARTIGO CIENTÍFICO EM:}

https://www.nucleodoconhecimento.com.br/enviar-artigo-cientifico-para-submissao 